\section{A Methodology to Measure Cervical Vertebral Bone Maturation in a Sample from Low-Income Children}

Luciana Barreto Vieira Aguiar ${ }^{1}$, Maria de Paula Caldas ${ }^{1}$, Francisco Haiter Neto $^{2}$, Glaucia Maria Bovi Ambrosano 3

\author{
'Department of Oral Radiology; \\ ${ }^{2}$ Department of Oral Diagnosis; \\ ${ }^{3}$ Department of Community \\ Dentistry, Piracicaba Dental \\ School, UNICAMP - University of \\ Campinas, Piracicaba, SP, Brazil \\ Correspondence: Profa. Dra. Glaucia \\ Maria Bovi Ambrosano, Avenida \\ Limeira, 901, Caixa Postal: 52, \\ 13414-903 Piracicaba, SP, Brasil. \\ Tel: +55-19-2106-5327.e-mail: \\ glaucia@fop.unicamp.br
}

\begin{abstract}
This study evaluated the applicability of the regression method for determining vertebral age developed by Caldas et al. (2007) by testing this method in children from low-income families of the rural zone. The sample comprised cephalometric and hand-wrist radiographs of 76 boys and 64 girls aged 7.0 to 14.9 years living in a medium-sized city in the desert region of the northeastern region of Brazil, with an $\mathrm{HDI}$ of 0.678 . C3 and $\mathrm{C} 4$ vertebrae were traced and measured on cephalometric radiographs to estimate the bone age. The average age, average hand-wrist age and average error estimated for girls and boys were, respectively, 10.62 and 10.44 years, 11.28 and 10.57 years, and 1.42 and 1.18 years. Based on these results, the formula proposed by Caldas et al. (2007) was not applicable to the studied population, and new multiple regression models were developed to obtain the children's vertebral bone age accurately.
\end{abstract}

Key Words: vertebral bodies, growth, puberty.

\section{Introduction}

Bone growth is a fundamental process in human development and it is almost entirely responsible for the increase in stature. It is known that bone tissue develops, grows and matures along defined lines, from a primary ossification center until it reaches the stage of completely developed bone (1).

Morphological maturity is inevitable in all individuals, with different growth spurts, occurring earlier in some individuals and later in others (2). Dental tissue mineralization, ossification in epiphyses and posterior fusion with the diaphyses, the beginning of the puberal growth spurt, variation in height and coming up of sexual characteristics are considered indicators of maturation $(2,3)$. In adolescence, there is a period in which growth occurs at a maximum rate, known as the pubertal growth spurt (4-6).

The use of hand and wrist or carpal radiographs to evaluate bone growth and maturation is due to the facts that the hand and wrist have a large number of ossification centers in a relatively small area, the radiographic technique is simple, and the patient is exposed to a small amount of radiation during the exam $(5,7)$.

In spite of the low radiation dose received by the carpal radiography technique, it consists in an additional exposure. Thus, to save available resources and reduce radiographic exposure, efforts have been made to use radiographs that form part of routine orthodontic documentation, as is the case of cephalometric radiographs $(4,6,8-12)$.

The lateral cephalometric radiographs routinely used in exams for orthodontic and/or functional orthopedic treatment may contain important information that requires attention and knowledge of the head and neck anatomy, as well as the cervical vertebrae (13). Therefore, changes in the size and shape of the vertebrae during the individual's growth may be used as an indicator of bone maturation $(8,14)$.

Nevertheless, there are still insufficient data that show the full effectiveness of the cervical vertebra method to justify replacement of the carpal method. Therefore, different populations may respond in a distinct manner to one and the same method of skeletal maturity evaluation, as their growth occurs in different ways (5).

Using cervical vertebra measurements, Mito et al. (8) conducted a study with the purpose of establishing the bone age of cervical vertebrae as a new index for the objective evaluation of skeletal maturation in cephalometric radiographs of Japanese girls. The bodies of vertebrae C3 and $\mathrm{C} 4$ were traced and measured at some points and were used to determine a regression equation. They observed that there was a high correlation between the vertebral and carpal bone ages in comparison with vertebral bone and chronological age. The authors suggested that vertebral bone age reflects skeletal maturity because it was close to the carpal bone age, and thus was considered a reliable method.

Caldas et al. (6) established two new formulas with the purpose of objectively evaluating skeletal maturation in Brazilian girls and boys, using the cephalometric radiographs of 128 girls and 110 boys in the age-range from 7.0 to 15.9 years, obtained from the files of the Radiology Clinic of the Piracicaba Dental School, UNICAMP, Brazil. The bodies of cervical vertebrae $\mathrm{C} 3$ and $\mathrm{C} 4$ were measured 
and a regression formula was developed to determine vertebral bone age. The results suggested that the method for establishing and evaluating skeletal maturation was reliable and could be applied to both boys and girls in the studied region.

Jaqueira et al. (15) compared the use of three cervical vertebral evaluation methods - Hassel-Farman (16), Baccetti et al. (17) and Seedat-Forsberg (18) - for establishing the skeletal maturation stage on radiographs of orthodontic patients between the ages of 7 and 49 years. The authors concluded that the three methods used demonstrated clinical applicability, however the method proposed by Baccetti et al. presented the best results, followed by those proposed by Hassel-Farman and Seedat-Forsberg.

Caldas et al. (19) evaluated the applicability of the vertebral bone age analysis method proposed by Caldas et al (6) in the different regions of the country, and concluded that the formulas developed in 2007 have shown to be reliable and could be used in the studied population.

Nutrient deficiencies in babies and children, generally associated with poverty in developing countries, are caused by multiple factors, including maternal malnutrition, incidence of supplementary foods low in calories and poor in nutrients, and a high rate of infections (20). Therefore it is conceivable that the combined effects of micronutrients, macronutrients, and/or groups of foods may influence the onset of puberty (21).

Based on this premise, the aims of this study were 1. to apply the regression model developed by Caldas et al. (2007) (6) in children of the rural zone of a small-size city located in the northeastern region of Brazil, with an HDI (Human Development Index) of 0.678; and 2. to develop new models to estimate the vertebral bone age in the studied population whenever the Caldas' was not applicable.

\section{Material and Methods}

This study began after approval by the Ethics Committee of the Piracicaba Dental School - UNICAMP (Protocol \#055/2007).

The sample was calculated considering a power of 0.80 and level of significance of 5\%, composed of children living in the rural area of Itabaiana, a medium-sized city located in the desert region of the State of Sergipe in the Brazilian northeastern region. This city has a HDI 0.678 , according to the Superintendence of Studies and Researches - SUPES, 2000, which is part of the Brazilian Government Program for Eradication of Child Labor (PETI - Programa de Erradicação do Trabalho Infantil, in Portuguese) aimed at the low-income population. The sample consisted of 140 individuals (76 boys and 64 girls) in the age-range between 7.0 and 14.9 years. Cephalometric radiographs and hand-wrist radiographs were taken. None of the patients had congenital or acquired malformation in the cervical vertebrae or hand and wrist.

Cephalometric radiographs were taken at a focusfilm distance of $1.52 \mathrm{~m}$. The individual was placed in the cephalostat, maintaining the medial sagittal plane perpendicular to the horizontal plane, and the Frankfurt plane parallel to the horizontal plane. The $x$-ray beam was directed at a vertical angle of $0^{\circ}$ and horizontal angle of $90^{\circ}$.

The cephalometric radiographs were used to calculate the vertebral bone age. The cervical vertebrae were handtraced on acetate film using a light box in a room with reduced luminosity, appropriate for this purpose. A dark paper mask was used so that excessive light from the light box would not interfere with the tracing.

Tracings were made of the anterior height of the cervical vertebra body $\left(\mathrm{AH}_{3,4}\right)$, height of the vertebra body $\left(\mathrm{H}_{3,4}\right)$, posterior height of the cervical vertebra body $\left(\mathrm{AP}_{3,4}\right)$ and anteroposterior length of the vertebra body $\left(\mathrm{AP}_{3,4}\right)$ for the third and fourth cervical vertebra respectively (Fig. 1).

The hand and wrist radiographs were taken with the left hand centralized on the metal film holder chassis, the palm surface facing the film, the axis of the middle finger in direct line with the forearm axis, fingers parted, the thumb forming an angle of $30^{\circ}$ with the index finger and the X-ray beam centered on third metacarpal bone, at a focus-film distance of $1.52 \mathrm{~m}$.

The hand and wrist radiographs were used to calculate the bone age evaluated by the TW3 method (22) in which the hand and wrist ossification centers (radius, ulna and some selected metacarpal bones and phalanges) were evaluated to obtain classification in the different stages. The hand and wrist radiographs were used as the gold standard for

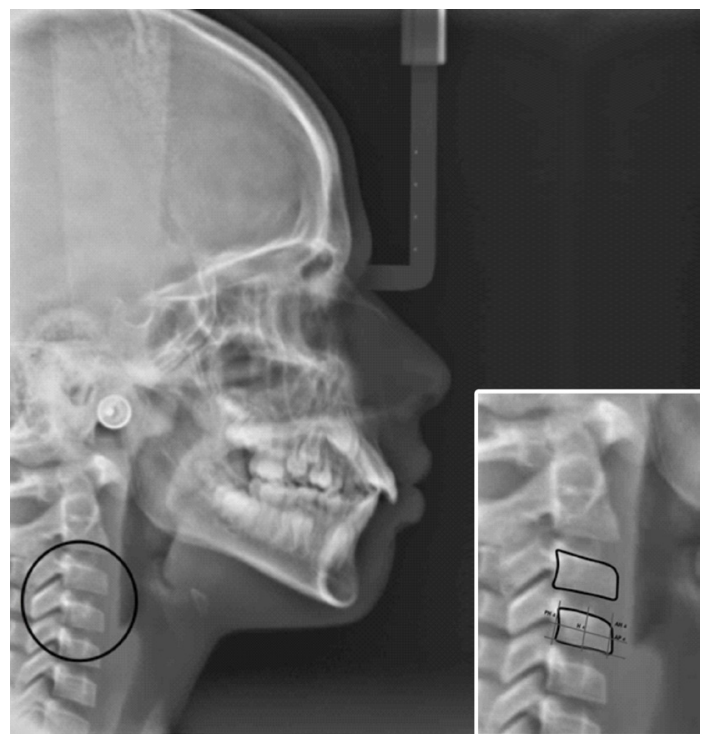

Figure 1. Delineation of C4 vertebral height and length. 
determining the reliability of vertebral bone age.

For examiner calibration by an evaluator experienced in this type of tracing, 40 randomly selected cephalometric and hand/wrist radiographs were traced, then traced again ten days later by two evaluators. To evaluate the calibration, the intraclass correlation was used, in which the following results were obtained: $0.968 ; 0.905 ; 0.959 ; 0.945$ for the measurements of $\mathrm{AH}_{3}, \mathrm{AP}_{3}, \mathrm{H}_{4}$ and $\mathrm{AP}_{4}$, respectively, in the male gender; and $0.984 ; 0.942 ; 0.986 ; 0.929$ for the measurements $\mathrm{AH}_{3}, \mathrm{AP}_{3}, \mathrm{H}_{4}$ and $A \mathrm{P}_{4}$, in the female gender.

Data were tabulated with each radiograph showing the patient's gender and the measurements performed in the vertebrae. The formula proposed by Caldas et al. (6) was applied for the female gender (estimated age = $\left.1.3523+6.7691 \times \mathrm{AH}_{3} / \mathrm{AP}_{3}+8.6408 \times \mathrm{AH}_{4} / \mathrm{AP}_{4}\right)$ and for the male gender (estimated age $=1.4892+11.3736 \times \mathrm{AH}_{3} /$ $\mathrm{AP}_{3}+4.8726 \times \mathrm{H}_{4}\left(\mathrm{AP}_{4}\right)$, where a multiple regression model estimates the vertebral bone age using $\mathrm{AH}, \mathrm{H}, \mathrm{PH}, \mathrm{AP}$ as independent variables. The mean ages and error (difference between vertebral and carpal age), and respective intervals of confidence were estimated.

As the data were not well adjusted to the tested models, as shown by the intervals of confidence and by the different mean error when compared with zero $(p<0.0001)$ by the t-test for a mean, new regression models were developed. For this purpose, multiple regression was used. Model adjustment was evaluated by Mallow's Cp Statistic, determination coefficient and graphic analysis of residues was performed. All analyses were performed in the statistical program SAS (Statistical Analysis System, SAS Institute, Cary, NC, USA, version 9.1, 2003).

\section{Results}

Figures 2 and 3 display the means of the parameters measured on the fourth cervical vertebrae in the cephalometric radiographs. The same trace was made on the $\mathrm{C} 3$ vertebrae. For $\mathrm{AH}_{3,4}, \mathrm{PH}_{3,4}, \mathrm{AP}_{3,4}, \mathrm{H}_{3,4}$ there was a

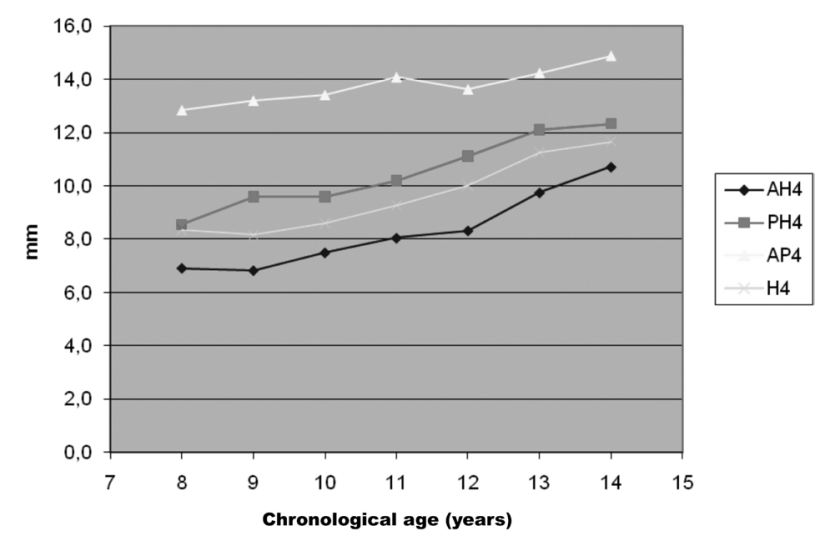

Figure 2. Average measurements of $\mathrm{C} 4$ vertebra in female volunteers. greater increase from 12 years of age, when the female gender sample was analyzed.

For the male gender sample, a greater increase in $\mathrm{AH}_{3,4}$ $\mathrm{PH}_{3,4}, \mathrm{H}_{3,4}$ was observed from 12 years of age, but the $\mathrm{AP}_{3,4}$ measurements presented a smaller variation with age.

Table 1 presents the means and intervals of confidence of the vertebral ages estimated by the model developed by Caldas et al. (6), carpal ages estimated by the TW3 method (22) and chronological ages as informed by the volunteers. From the analysis of data for the female gender, it was observed that the interval of confidence of $95 \%$ for vertebral age was 10.35 to 10.89 years and for carpal age was 10.89 to 11.67 years. The mean error was 1.42 years with an interval of confidence of 1.20 to 1.64 years. For the male gender, the interval of confidence of $95 \%$ for vertebral age was 10.16 to 10.72 years and for carpal age it was 10.21 to 10.93 years, with a mean error of 1.18 years. It was observed that for the volunteers from the city of Itabaiana, the Caldas et al. (6) model estimated a lower age than the carpal and chronological ages, with a mean error of 1.42 in comparison with the carpal age for the female gender and 1.18 years for the male gender $(p<0.0001)$.

Due to the high mean error, differing significantly from zero $(p<0.0001)$, the formula proposed by Caldas et al. (6) could not be applied to this population. Therefore, by means of multiple regression analysis, a method to determine the regression models was developed to obtain the vertebral bone age (Tables 2 and 3 ).

\section{Discussion}

Knowledge of patients' growth and development is important in orthodontic and orthopedic treatment planning. To study children's growth and development, various physical characteristics have to be considered, such as weight, height, bone age and dental age, which may be compared with the patterns observed in large groups of healthy children (10).

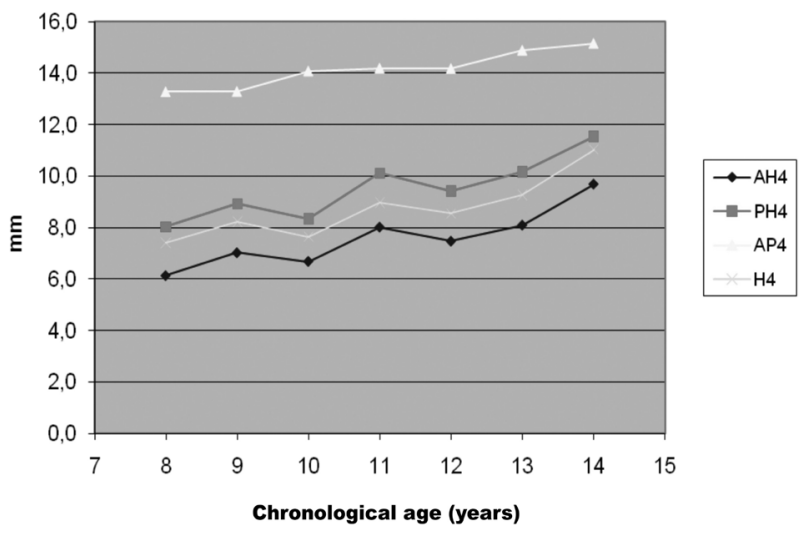

Figure 3. Average measurements of $\mathrm{C} 4$ vertebra in male volunteers. 
One of the means of evaluating bone age is by the radiographic analysis of hand and wrist, but there is concern about the dose of radiation to which children and adolescents will be exposed. New techniques are used to avoid taking additional radiographs (4). Cephalometric analysis on lateral teleradiographs has been proven efficient, as it is part of orthodontic documentation, and it is possible to visualize the cervical vertebrae and their changes for the evaluation of bone age.

Knowing that the evaluation of bone maturation by means of the cervical vertebrae is a relatively new technique in comparison with the technique performed using the hand and wrist, various authors have conducted researches based on clinical inspection and measurements of the vertebrae in large groups of healthy children, and researches in children with low HDI were found in the literature.

The present study tested the regression model developed by Caldas et al. (6) in children of the rural zone of a city located in the desert region of Brazil, with a low HDI (0.678) and since the model did not adjust well to this population, a new model was developed to estimate the vertebral bone age in the studied population.

Mito et al. (8) also developed a regression model to estimate bone age by means of cervical vertebrae, however, it was not possible to apply it in the studied population because this model was estimated among Japanese children and adolescent girls, who differ from the subjects in this research.

For the female gender, there was difference in the results found by Caldas et al. (6) and Mito et al. (8) for the age-range between 8 and 14 years, for both $\mathrm{C} 3$ and $\mathrm{C} 4$ vertebrae. This is because the study by Caldas et al. (6) was conducted in the city Piracicaba, SP, in the southeastern region of Brazil without distinction of social condition, and the study by Mito et al. (8) was conducted in a population of Japanese girls. The bone ages estimated by the equations developed by Caldas et al. (6) are also not reliable for our population because mean errors of 1.42 and 1.18 years were found in comparison with carpal bone age for the female and the male genders.

Caldas et al. (19) evaluated the applicability of the method for the analysis of vertebral bone age, proposed by Caldas et al. (6) in the different regions of Brazil and concluded that the established formulae have been proven reliable and could be used in the studied population.

The difference found in the present research in comparison with those of Caldas et al. (6) and Caldas et al. (19), both for the female and male genders, may be explained by the fact that our population was of a rural zone with a low HDI (0.678) when compared with Piracicaba's HDI of 0.836. Therefore, new formulas were developed because the mean errors found between the difference in vertebral and carpal age were over 1 year, which proved that the formula developed by Caldas et al. (6) was not valid for the studied population.

The variables that compose the new model estimated for the female $\left(\mathrm{H}_{3}\right.$, and $\left.\mathrm{AP}_{4}\right)$ and male $\left(\mathrm{AH}_{3}\right.$ and $\left.\mathrm{AP}_{4}\right)$ genders differed from those used by Caldas et al. (6) and Mito et al. (8) making the regression model more faithful for obtaining vertebral bone age in this population, with $\mathrm{R}^{2}$ adjusted 0.6751 for the female and 0.6209 for the male gender.

It is known that different populations may respond in a different way to one and the same method of skeletal maturity evaluation, as the growth occurs in different ways (5). Due to this fact, differences were found between the authors, and further studies are required to evaluate these discrepancies, as studies related to vertebral bone maturation in a population with low HDI are scarce in

Table1. Mean (95\% confidence interval) of age by gender

\begin{tabular}{|c|c|c|c|c|c|}
\hline \multirow{2}{*}{ Gender } & \multicolumn{3}{|c|}{ Age } & \multirow{2}{*}{$\frac{\text { Error }^{\#}}{\text { (years) }}$} & \multirow{2}{*}{$\begin{array}{c}\mathrm{p}^{1} \\
\text { (t-test for averages) }\end{array}$} \\
\hline & Vertebral* & Carpal & Chronological & & \\
\hline Female & $10.62(10.35-10.89)$ & $11.28(10.89-11.67)$ & $11.58(10.89-11.67)$ & $1.42(1.20-1.64)$ & $<0.0001$ \\
\hline Male & $10.44(10.16-10.72)$ & $10.57(10.21-10.93)$ & $11.64(11.32-11.96)$ & $1.18(1.00-1.36)$ & $<0.0001$ \\
\hline
\end{tabular}

${ }^{1}$ t-test comparing the error with zero.* Estimated by the formula proposed by Caldas et al. 2007. \# Difference between the vertebral and carpal ages.

Table 2. New model for females

\begin{tabular}{lccc}
\hline Variable & Parameter estimate & Standard error & P value \\
\hline Intercept & -2.2172 & 1.7790 & 0.2174 \\
$\mathrm{H}_{3}$ & 0.9291 & 0.1136 & $<0.0001$ \\
$\mathrm{AP}_{4}$ & 0.3089 & 0.1536 & 0.0487 \\
\hline
\end{tabular}

Adjusted $\mathrm{R}^{2}=0.6751$. Estimated age $=-2.2172+0.9291 \mathrm{xH}_{3}+0.3089 \times \mathrm{AP}_{4}$.
Table 3. New model for males

\begin{tabular}{lccc}
\hline Variable & Parameter estimate & Standard error & P value \\
\hline Intercept & 1.5333 & 1.9770 & 0.4406 \\
$\mathrm{AH}_{3}$ & 0.5896 & 0.1313 & $<0.0001$ \\
$\mathrm{AP}_{4}$ & 0.3619 & 0.1553 & 0.0226 \\
\hline
\end{tabular}

Adjusted $\mathrm{R}^{2}=0.6209$. Estimated age $=1.5333+0.5896 \times \mathrm{AH}_{3}+0.3619 \times \mathrm{AP}_{4}$ 
the literature.

Based on analysis of the results, it may be concluded that the model proposed by Caldas et al. (6) for estimating the vertebral bone age in children in the Brazilian city of Piracicaba, in the southeastern region of the country, was not applicable to children from low-income families living in the rural zone of the Brazilian city of Itabaiana, SE, in the northeastern region of the country. The new models developed for the objective evaluation of vertebral bone age in the studied population were found to be reliable.

\section{Resumo}

0 objetivo deste estudo foi avaliar a aplicabilidade do método de análise para determinar a idade vertebral proposto por Caldas et al., 2007 em crianças de baixa renda. A amostra se constituiu de radiografias cefalometricas e carpais de 76 meninos e 64 meninas com idade entre 7,0 a 14,9 anos que vivem em zona rural de um municipio sergipano. 0 s corpos das vértebras $\mathrm{C} 3$ e C4 foram traçadas e mensuradas e em seguida as idades ósseas foram estimadas. A idade media estimada para as meninas foi de 10,62 anos e a idade óssea carpal foi de 11,28 anos; o erro médio de 1,42 anos. A idade media estimada para os meninos foi de 10,44 anos e a idade óssea carpal foi de 10,57 anos com erro médio de 1,18 anos. Baseado nos resultados, o modelo proposto por Caldas et al. (2007) não pode ser aplicada na população estudada, e portanto novos modelos de regressão foram desenvolvidos.

\section{References}

1. Sachan K, Sharma VP, Tandon P. A correlative study of dental age and skeletal maturation.Indian J Dent Res 2011;22:882-882.

2 Mahajan S. Evaluation of skeletal maturation by comparing the hand wrist radiograph and cervical vertebrae as seen in lateral cephalogram. Indian J Dent Res 2011;22:309-316.

3. Franchi L, Baccetti T, McNamara Jr. JA. Mandibular growth as related to cervical vertebral maturation and body height. Am J Orthop Dentofacial Orthop 2000;118:335-340.

4 Zhao XG, Lin J, Jiang JH, Wang $0, \mathrm{Ng}$ SH. Validity and reliability of a method for assessment of cervical vertebral maturation. Angle Orthod 2012;82:229-234.

5. Damian MF, Woitchunas FE, Cericato G0, Cechinato F, Moro G, Masochin ME, et al.. Reliability and correlation analysis of two skeletal maturation evaluation indexes: hand-wrist index and cervical vertebrae index. R Dental Press Ortodon Ortop Facial 2006;11:110-120.

6. Caldas MP, Ambrosano GMB, Neto FH. New formula to objectively evaluate skeletal maturation using lateral cephalometric radiographs. Braz Oral Res 2007;21:330-335.
7. Mahjan S. Evaluation of skeletal maturation by comparing the hand wrist radiograph and cervical vertebrae as seen in lateral cephalogram. Indian J Dent Res 2011;22:309-316.

8. Mito T, Sato K, Mitani H. Cervical vertebral bone age in girls. Am J Orthop Dentofacial Orthop 2002;122:380-385.

9. San Román P, Palma JC, Oteo MD, Nevado E. Skeletal maturation determined by cervical vertebrae development. Eur J Orthod 2002;24:303-311.

10. Franco AA, Santana AH, Santana IS, Melo MFB, Junior JHS. Radiographic determination of skeletal maturity and the importance to diagnosis and orthodontic treatment. Ortodontia 1996;29:53-59.

11. Camargo GTL, Cunha TGE. Study of the synchronism among skeletal age, dental age and vertebral age with the chronological age. SOTAU R Virtual Odontol 2007;2:2-7.

12. Plasschaert AS, Generoso R, Armond MC, Paixão MPM, Rocha BEPM. Comparative study of inspectional and computerized analyses of cervical vertebrae bone maturation. Rev ABRO 2008;9:33-41.

13. Tetradis $\mathrm{S}$, Kantor ML. Prevalence of skeletal and dental anomalies and normal variants seen in cephalometric and other radiographs of orthodontic patients. Am J Orthop Dentofacial Orthop 1999;116:572577.

14. Flores-Mir C, Burgess CA, Champney M, Jensen RJ, Pitcher MR, Major PW. Correlation of skeletal maturation stages determined by cervical vertebrae and hand-wrist evaluations. Angle Orthod 2006;76:1-5.

15. Jaqueira LMF, Armond MC, Pereira $\amalg$, Alcântara CEP, Marques LS. Determining skeletal maturation stage using cervical vertebrae: evaluation of three diagnostic methods. Braz Oral Res 2010;24:433437.

16. Hassel B, Farman AG. Skeletal maturation evaluation using cervical vertebrae. Am J Orthod Dentofacial Orthop 1995;107:58-66.

17. Baccetti T, Franchi L, McNamara JA Jr. An improved version of the cervical vertebral maturation (CVM) method for the assessment of mandibular growth. Angle Orthod 2002;72:316-223.

18. Seedat $A K$, Forsberg $C D$. An evaluation of the third cervical vertebra (C3) as a growth indicator in Black subjects. SADJ 2005;60:156,158160.

19. Caldas MP, Ambrosano GMB, Neto FH. Computer-assisted analysis of cervical vertebral bone age using cephalometric radiographs in Brazilian subjects. Braz Oral Res 2010;24:120-126.

20. Kirby $M$, Danner E. Nutritional deficiencies in children on restricted diets. Pediatr Clin N Am 2009;56:1085-1103.

21. Cheng G, Gerlach S, Libuda L, Kranz S, Günther ALB, Karaolis-Danckert $\mathrm{N}$, et al.. Diet quality in childhood is prospectively associated with the timing of puberty but not with body composition at puberty onset. $J$ Nutr 2010;140:95-102.

22. Tanner JM, Whitehouse RH. Standards for skeletal maturation. Paris: International Children's Center; 1959.

Received September 2, 2011 Accepted December 17, 2012 